\title{
The evaluation of dizziness in elderly patients
}

\author{
N. Ahmad, J.A. Wilson ${ }^{1}$, R.M. Barr-Hamilton ${ }^{2}$, D.M. Kean ${ }^{3}$ and \\ W.J. MacLennan
}

Geriatric Medicine Unit, City Hospital, Edinburgh and Departments of ${ }^{1}$ Otolaryngology, ${ }^{2}$ Audiology and ${ }^{3}$ Radiology, Royal Infirmary, Edinburgh, UK

\begin{abstract}
Summary: Twenty-one elderly patients with dizziness underwent a comprehensive medical and otoneurological evaluation. The majority had vertigo, limited mobility and restricted neck movements. Poor visual acuity, postural hypotension and presbyacusis were also frequent findings. Electronystagmography revealed positional nystagmus in 12 , disordered smooth pursuit in 18 , and abnormal caloric responses in nine. Magnetic resonance imaging showed ischaemic changes in six out of eight patients. Although dizziness in the elderly is clearly multifactorial, the suggested importance of vertebrobasilar ischaemia warrants further consideration as vertigo has been shown to be a risk factor for stroke.
\end{abstract}

\section{Introduction}

More than one third of individuals over the age of 65 years experience recurrent attacks of dizziness. ${ }^{1}$ Serious consequences include a high incidence of falls in patients with non-rotating dizziness, and an increased risk of stroke in those with vertigo (a sensation of movement relative to surroundings). ${ }^{1,2}$

The causes of dizziness are legion. ${ }^{3}$ Its diagnosis, therefore, presents the clinician with a considerable challenge particularly in old people in whom ageing of the vestibular neuroepithelium or other components of the balance mechanism may be responsible for the symptom. ${ }^{4} \mathrm{~A}$ further problem is that adequate investigation may require expertise in a wide range of disciplines including geriatrics, neurology, neurophysiology, radiology and otology. Techniques implemented have included questionnaire surveys, clinical assessment of gait and balance, force platform measurements, ${ }^{5,6}$ echocardiography, ${ }^{7}$ electronystagmography (ENG) ${ }^{8}$ and imaging of the cental nervous system. ${ }^{9-12}$ The latter two tests are time consuming and their diagnostic value has yet to be fully established.

The aim of this study was to compare the clinical evaluation of elderly patients with dizziness by a geriatrician with an otolaryngology (ENT) assessment and the results of electronystagmography and, where possible, magnetic resonance imaging (MRI).

Correspondence: Professor W.J. MacLennan, M.D., F.R.C.P., Geriatric Medicine Unit, City Hospital, Edinburgh EH10 5SB, UK.

Accepted: 5 February 1992

\section{Patients and methods}

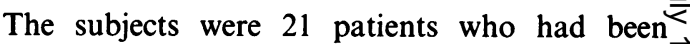
referred to either the care of the elderly unit or ENT $\vec{O}$ Department in Edinburgh for the investigation of? dizziness. There were five males and 16 femaks aged $68-95$ years (median $=81$ years). A carefuny structured history was used to evaluate indoor and outdoor mobility, and symptoms of lightheadedness, vertigo and unsteadiness. Physical examina- 0 tion by a physician included measurement of $\overrightarrow{\vec{P}}$ passive movement in the neck, hips and knees, and $\frac{3}{3}$ of lower limb muscle power, tone and reflexes. Peripheral cerebellar signs were sought ando measurement of supine and standing (at 2 minutes) blood pressures performed. A Snellen chart was 3 used to test visual acuity. Balance was graded on a 7-point scale ranging from being unable to sit 3 . steadily, to being able to stand steadily for $20 \AA$ seconds with no aid, with a long base and with eyes $₹$ closed. ${ }^{13}$ Cognitive function was evaluated by com-을 pleting a brief mental status questionnaire. ${ }^{14}$

Otolaryngological examination was performed independently by a second observer and included $\mathrm{a}=$ further clinical assessment, otoscopy and a briefo neurological examination including corneal reflex $N_{0}$ testing. Pure tone audiometry was carried out using $\mathbb{E}^{-}$ a Kamplex AC3 audiometer. Threshold measure- 0 ments were performed at octave frequencies from $250 \mathrm{~Hz}$ to $8 \mathrm{kHz}$ by air conduction and $500 \mathrm{~Hz}$ to $\frac{\mathrm{C}}{\varnothing}$ $4 \mathrm{kHz}$ by bone conduction. Air conduction thres- $\stackrel{\infty}{\sim}$ holds at $0.5,2,4$ and $8 \mathrm{kHz}$ were averaged. Where 0 indicated, acoustic admittance measurements were $\overline{0}$ performed using a Gray Stad GSI-33; and brain- $\stackrel{\mathbb{Q}}{\circ}$ stem electrical response (BSER) audiometry using $\mathbb{\otimes}$ an Amplopid Mk10 system (stimulus 11 clicks/ 
second and 70 clicks/second at $90 \mathrm{~dB}$ nHL intensity).

In all the vestibular tests, ENG was performed with a Peters AP210 recorder. Where practicable, recordings were made (with eyes open and with eyes closed) of spontaneous nystagmus, positional nystagmus and pendulum tracking. Bithermal caloric testing (again using ENG) was performed, in most cases using water at $44^{\circ} \mathrm{C}$ and at $30^{\circ} \mathrm{C}$, with 30 seconds irrigation. In cases where a perforated drum was present or suspected, air at $50^{\circ} \mathrm{C}$ and $24^{\circ} \mathrm{C}$ was used with 50 seconds irrigation. Caloric responses were recorded with the patient's eyes closed, and after about 60 seconds recording the patient was instructed to open the eyes to assess the effect of optic fixation (OF) on thermally induced nystagmus.

MRI was performed using a 0.08 Telsa resistive system situated in the Royal Infirmary, Edinburgh ${ }^{15}$ in those patients where a central causative factor was suspected from clinical or ENT findings. Transverse and sagittal $T_{1}$ - and $T_{2}$-weighted images were obtained on all subjects. ( $T_{1}$-weighted images from an interleaved saturation recovery + inversion recovery sequence with $T_{\mathrm{R}}=1$ second, $T \mathrm{I}=200$ milliseconds, $T_{2}$-weighted images from a spin echo sequence with $T_{\mathrm{R}}=1.4$ seconds, $T_{\mathrm{E}}=96$ milliseconds).

\section{Results}

Of the 21 patients recruited, 19 completed all parts of the study. One patient defaulted from the ENT clinic and a second during the course of her investigation was admitted as an emergency with drowsiness following a fall. A CT scan revealed a space occupying lesion with midline shift and hydrocephalus. The lesion, a meningioma, was subsequently excised with good postoperative recovery.

Table I gives details of the clinical features identified in the 21 patients while Table II gives details on a clinical evaluation of balance in all but one of them.

The results of pure tone audiometry showed an average threshold of $50 \mathrm{~dB}$ HL (range 29 to 100 , $\mathrm{SD}=18 \mathrm{~dB}$ ) in the right ear with similar readings for the left side. In most patients the pattern was consistent with simple presbyacusis but three patients' average thresholds at the frequencies tested showed an interaural asymmetry of greater than $15 \mathrm{~dB}$. BSER audiometry on one of these showed an N5 wave interaural latency difference greater than our upper limit of normal of 0.3 milliseconds. In accordance with our routine clinical practice, therefore, a CT scan was performed. No intracranial lesion was detected. One patient had a slight low tone component on the
Table I Clinical features of 21 dizzy elderly patients. Only abnormal features are noted

\begin{tabular}{|c|c|}
\hline Feature & $\begin{array}{l}\text { Number of } \\
\text { patients }\end{array}$ \\
\hline $\begin{array}{l}\text { Symptom } \\
\text { vertigo } \\
\text { falls } \\
\text { deafness } \\
\text { nausea and vomiting } \\
\text { tinnitus } \\
\text { diplopia }\end{array}$ & $\begin{array}{r}15 \\
6 \\
3 \\
2 \\
1 \\
1\end{array}$ \\
\hline $\begin{array}{l}\text { Walk with aid (zimmer/stick) } \\
\text { Mobile indoors only } \\
\text { Mobile }<300 \text { yards outdoors }\end{array}$ & $\begin{array}{r}10 \\
7 \\
6\end{array}$ \\
\hline $\begin{array}{l}\text { Limitation of neck movements } \\
\text { with pain } \\
\text { with dizziness }\end{array}$ & $\begin{array}{r}12 \\
3 \\
2\end{array}$ \\
\hline $\begin{array}{l}\text { Visual acuity }>\mathrm{N} 18 \\
\text { bilateral } \\
\text { unilateral }\end{array}$ & $\begin{array}{l}3 \\
3\end{array}$ \\
\hline $\begin{array}{l}\text { Postural systolic BP drop of } \\
>20 \mathrm{mmHg} \\
\text { symptomatic }\end{array}$ & $\begin{array}{l}5 \\
2\end{array}$ \\
\hline Abnormal lower limb findings & 0 \\
\hline $\begin{array}{l}\text { Truncal ataxia } \\
\text { Horizontal jerk nystagmus }\end{array}$ & $\begin{array}{l}1 \\
3\end{array}$ \\
\hline Mental test score $<8 / 10$ & 2 \\
\hline
\end{tabular}

Table II Balance gradings recorded during clinical examination of patients

\begin{tabular}{ll}
\hline Balance characteristics & $\begin{array}{c}\text { Number of } \\
\text { patients }\end{array}$
\end{tabular}

Unsafe seated

0

Safe seated, unsafe standing

2

Steady standing for 20 seconds with aid

Steady standing for 20 seconds with no aid on wide base

Steady standing for 20 seconds with no aid on narrow base

Steady standing for 20 seconds with no aid on long base

Steady standing for 20 seconds with no aid

Total

1

4

20

right side associated with a flat tympanogram. A right myringotomy was performed but the middle ear space was found to be dry and the dizziness was unaltered after this procedure. The ENG results are summarized in Table III. Four patients had limited examinations, two because of restricted head movements and two because of nausea and vomit- 
Table III Electronystagmographic findings in 20 patients

\begin{tabular}{lc}
\hline Observation & $\begin{array}{c}\text { Number of } \\
\text { patients }\end{array}$ \\
\hline Calibration overshoot & 1 \\
No overshoot & 19 \\
Positional nystagmus absent & 8 \\
Amplitude & 2 \\
$<2$ 0/s & 7 \\
$2-40 / \mathrm{s}$ & 1 \\
$>5$ 0/s & 2 \\
test restricted & 2 \\
Pendulum tracking normal & 5 \\
mild disorder & 13 \\
gross break-up & 9 \\
Caloric responses normal & 7 \\
unilateral canal paresis & 2 \\
bilateral canal paresis & 2 \\
not tested & \\
Effect of optic fixation on caloric nys- & \\
tagmus & \\
total suppression & 9 \\
variable/partial suppression & 3 \\
no effect & 7 \\
enhancement & \\
\hline
\end{tabular}

$0 / \mathrm{s}=$ degrees per second .

ing during any caloric testing. The patient with gross calibration overshoot had the meningioma described above. The other clear central ENG signs included a gross break-up of pendulum tracking, and the failure of $\mathrm{OF}$ to suppress caloric nystagmus. Ten patients were referred for MRI, but two defaulted. Two of the scans were normal but the other six showed vascular type lesions - three periventricular diffuse, one parietal, one temporoparietal with global atrophy and one leucoencephalopathy. None showed cerebellar or brainstem lesions but one of the normal scans was of poor quality due to movement. A week later the patient died and an autopsy identified a medullary infarction. There were no significant movement artefacts in the remaining scans.

When ENG and MRI scan findings were compared with clinical observations, it emerged that the two patients with bilateral canal paresis had clinical evidence of peripheral vestibular dysfunction (one labyrinthitis, one Ménière's syndrome). Five of the seven patients with unilateral canal paresis had the clinical diagnosis of vertebrobasilar ischaemia, and the other two were thought initially to have Ménière's disease. There was a good correlation between abnormalities in MRI scans, and clinical evidence of cerebrovascular disease. An exception was that two patients with normal scans had signs and symptoms of vertebrobasilar ischaemia.

\section{Discussion}

Dysequilibrium in old people is linked to damageo to vestibular end organs or to their central con-음 trol $^{16}$ and to a multiplicity of sensory defects $\frac{\bar{\rho}}{\frac{1}{2}}$ such as impaired vibration sense, which is closely $\mathbb{Q}^{\mathbb{Q}}$ correlated with ataxia. ${ }^{17,18}$ Falls are also assoc- 0 iated with many causes of ataxia or dizziness? whose relative importance can be hard to deter-. mine. ${ }^{19}$ In the present study a detailed clinical $\vec{\omega}$ assessment was accompanied by an otoneuro- $\stackrel{\omega}{\circ}$ logical and neuroradiological work-up. As in many previous studies, we found a high preva- 3 . lence of postural hypotension ${ }^{20}$ but this waso symptomatic in only two patients which empha-io sizes the variable causal association of postural hypotension and dizziness. The severity of the drop, the absolute level of the steady systolico pressure, and the presence of cerebral atherosclerosis may all be critical determinants of this relationship. ${ }^{21}$

It is noteworthy that almost one third of patients had major visual defects (Table I). Poorce vision interferes with visuo-vestibular interactiogs ș and may have been a major contributory factoro to the finding that only two of our patients hadd a normal ENG response to the pendulum têst (Table III). ${ }^{22}$ Further information on the vesti-品 bulo-ocular reflex was elicited by assessing sup-市 pression of caloric nystagmus by optic fixation. Abnormalities were elicited in more than half theo patients. While these could have been linked to the visual defects elicited in many of the subjects, similar changes could have been the result of mid-brain ischaemia.

The vestibular changes reported to be associat ed with ageing include the observation that caloric testing induces nystagmus with a highero frequency, but lower amplitude, and with greater 3 lateral asymmetry. ${ }^{23}$ The cause of the combina-o tion of impaired suppression of nystagmus by $\mathrm{OF}$ and the high prevalence of both canal paresiso and positional nystagmus in the present series may have been due to transient central (vertebro- $N$ basilar) ischaemia, to cervical vertigo associated N with spondylosis, or to benign paroxysmal posi-N tional nystagmus in the present series. Cervical ${ }_{\sigma}^{\infty}$ spine radiography is unhelpful in this situation. ${ }^{24,25}$ The importance of brainstem ischaemia as a cause of dizziness in our subjects is sup- $\infty$ ported by the higher incidence of rotatory ver- 0 tigo (Table I) identified as an important risk factor for stroke in the United Kingdom. ${ }^{1} A \stackrel{\vec{\Phi}}{ }$ recent clinical review attests that the only certain $\vec{D}$ way of establishing this diagnostic is to perform 
four vessel angiography. ${ }^{26}$ There are clear logistic and ethical objections to this diagnostic approach in our group of frail elderly subjects in whom surgery is inappropriate. In a previous study of MRI scans, limited cooperation by the elderly patients resulted in many poor quality examinations. $^{12}$ We obtained good quality images in all but one subject whose suboptimal scan may account for the failure to identify a brainstem infarct. When interpreting the high prevalence of infarction demonstrated in the remaining MRI scans it should be remembered that we did not have a control group, and that there may be an equal prevalence of MRI abnormalities in elderly patients with dizziness and age-matched controls. ${ }^{12}$

This first few months' experience of a multidisciplinary approach to the investigation of elderly patients with dizziness suggests that it is practical and that it provides a high diagnostic yield of neuro-otological and radiological abnormalities.

\section{References}

1. Evans, J.G. Transient neurological dysfunction and risk of stroke in an elderly English population: the different significance of vertigo and non-rotating dizziness. Age Ageing 1990, 19: 43-49.

2. Prudham, D. \& Evans, J.G. Factors associated with falls in the elderly: a community study. Age Ageing 1990, 10: 141-146.

3. Fowler, H.M.A. Dizziness and vertigo. $\mathrm{Br}$ Med J 1984, 288: 1739-1743.

4. Belal, A. \& Glorig, A. Dysequilibrium of ageing (presbystasis). J Laryngol Otol 1986, 100: 1037-1041.

5. Pyykko, I. \& Jantti, A.H. Postural control in the oldest olds. Adv Oto-rhino-laryngol 1988, 41: 146-151.

6. Lynch, S.J., Nayak, U.S. \& Isaacs, B. Positional and optokinetic nystagmus in healthy old people. Age Ageing 1989, 14: 122-128.

7. Kinney, E.L. \& Wright, R.J. Should echocardiography be used to screen dizzy patients? Angiology 1988, 39: 902-906.

8. Baloh, R.W., Honrubia, A.V. \& Jacobson, K. Benign positional vertigo: clinical and oculographic features in 240 cases. Neurology 1983, 37: 371-378.

9. Bugousslavsky, J., Fox, A.J., Banett, H.J.M. et al. Clinicotopographic correlation of small vertebrobasilar infarct using magnetic resonance imaging. Stroke 1986, 17: 929-938.

10. Andreula, C.I., Camicia, M., Lorusso, I. et al. Clinical and CT parametry in degenerative cerebellar atrophy in aged patients. Neuroradiology 1989, 26: 29-30.

11. Ojala, M., Ketonen, L. \& Palo, J. The value of CT and very low field MRI in the etiological diagnosis of dizziness. Acta Neurol Scand 1988, 78: 26-29.

12. Day, J.J., Freer, C.E., Dixon, A.K. et al. Magnetic resonance imaging of the brain and brain stem in elderly patients with dizziness. Age Ageing 1990, 19: 144-150.

13. Gabell, A. \& Simons, M.A. Balance coding. Physiotherapy 1982, 68: 286-288.

14. Wilson, L.A. \& Brass, W. Brief assessment of the mental status in geriatric domiciliary practice: the usefulness of the mental status questionnaire. Age Ageing 1973, 2: 92-101.
15. Kean, D.M., Smith, M.A., Douglas, R.H.B. \& Best, J.J.K. A description of a low field resistive magnetic resonance imaging system and its application in imaging midline central nervous system pathology. Clin Radiol 1986, 37: 211-217.

16. Hollander, J. Dizziness. Sem Neurol 1987, 7: 317-335.

17. Jenkins, J.A., Truman, J.M., Gulya, A.J. et al. Dysequilibrium of ageing. Otolaryngol Head Neck Surg 1989, 100: 272-282.

18. Brocklehurst, J.C., Robertson, D. \& James-Groom, P. Clinical correlates of sway in old age - sensory modalities. Age Aging 1982, 11: 1-10.

19. Sharma, J.C. \& MacLennan, W.J. Causes of ataxia in patients attending a falls laboratory. Age Ageing 1988, 17: 94-102.

20. MacLennan, W.J., Hall, M.R.P. \& Timothy, J.I. Postural hypotension in old age: is it a disorder of the nervous system or of blood vessels? Age Ageing 1980, 9: 25-32.

21. Wollner, L., McCarthy, S.I., Soper, N.D. \& Macey, D.J. Failure of cerebral autoregulation as a cause of brain dysfunction in the elderly. $\mathrm{Br}$ Med J 1979, 1: 1117-1118.

22. Wall, C., Black, F.O. \& Hunt, A.E. Effects of age, sex and stimulus parameters upon vestibulo-ocular responses to sinusoidal rotation. Acta Otolaryngol 1984, 98: 270-278.

23. Van Der Laan, F.L. \& Oosterveld, W.J. Age and vestibular function. Aerospace Med 1974, 45: 540-547.

24. Heller, C.A., Stanley, P., Lewis-Jones, B. \& Heller, R.J. Value of X-ray examinations of the cervical spine. Br Med J 1983, 287, 1276-1278.

25. Adams, K.R.H., Yung, M.W., Lye, M. \& Whitehouse, G.H. Are cervical spine radiographs of value in elderly patients with vertebrobasilar insufficiency. Age Ageing 1986, 15: 57-59.

26. Ausman, J.I., Shrontz, C.E., Pearce, J.E., Diaz, F.G. \& Crecelius, J.L. Vertebro-basilar insufficiency - a review. Arch Neurol 1985, 42: 803-808. 